\title{
Influence of Phosphorus Content and Quenching/Tempering Temperatures on Fracture Toughness and Fatigue Life of SAE 5160 Steel
}

\author{
Danilo Borges Villarino de Castro*, Jaime Milan Ventura, Cassius Olivio Figueiredo Terra Ruckert, \\ Dirceu Spinelli, Waldek Wladimir Bose Filho
}

\author{
Department of Materials, Aeronautics and Automotive Engineering, \\ Engineering School of São Carlos, University of São Paulo (SMM-EESC-USP), \\ Av. Trabalhador São-Carlense, 400, Parque Arnold Schmidt, \\ CEP 13566-590, São Carlos, SP, Brazil
}

Received: May 18, 2010; Revised: November 30, 2010

\begin{abstract}
This study investigates the influence of quenching/tempering temperatures on the fracture toughness and fatigue life of SAE 5160 steel, considering different phosphorus contents. Quenching and tempering treatments were applied to samples removed from different bars of commercial SAE 5160 steel with different P content. Three different austenitizing temperatures for quenching: 850, 900 and $1000{ }^{\circ} \mathrm{C}$ and a constant holding time of 15 minutes were used. The oil temperature for quenching was kept at $66^{\circ} \mathrm{C}$ and the tempering conditions were 470,500 and $530{ }^{\circ} \mathrm{C}$ with the necessary time for a final hardness of $45 \pm 3 \mathrm{HRC}$. Therefore, the heat treatments cycles were applied to specimens containing low (0.012 wt. (\%)), medium $(0.017$ wt. (\%)) and high (above 0.025 wt. (\%)) phosphorus contents, in order to observe the effects of this element on the susceptibility of these steels to enhance quench and tempering embrittlements. The Charpy tests results showed that the phosphorus content analyzed in this work has caused embrittlement, even in the bars with the lowest $\mathrm{P}$ content, leading to intergranular fracture. However, if the nucleation life is taken into consideration, this embrittlement has no effect on the nucleation fatigue life of the component.
\end{abstract}

Keywords: 5160 steel, phosphorus, austenitizing, tempering

\section{Introduction}

It was observed that in the SAE 5160 steel steels used to make springs, the $\mathrm{P}$ content may ranges from 0.010 to 0.025 wt. (\%). Manufacturers consider that this concentration does not affect the impact and the fatigue performance of this component, which is highly requested in the automotive industry ${ }^{1}$. By knowing the negative effects of $\mathrm{P}$, this study aims to bring more light in the influence of $\mathrm{P}$ content, considering the regular alloying limits content found in the SAE 5160 steel bars, on both: the impact toughness and on the fatigue life.

It has been known that low-carbon alloy and plain-carbon steels are susceptible to intergranular fracture along the prior austenite grain boundaries, depending on their chemical compositions and heat treatment. In 1995 Krauss found a ductile fracture transition for intergranular fracture for steels with more than 0.5 wt. (\%) carbon in low-temperature tempered martensite steels ${ }^{2}$. Steels with higher $\mathrm{C}$ content submitted to tensile or bending stresses are highly susceptible to intergranular embrittlement phenomenon under asquenched and low-temperature tempered conditions. As tempering does not promote intergranular fracture, i.e., this embrittlement phenomenon can occur during the austenitizing or quenching process, it is called quench embrittlement $(\mathrm{QE})^{3}$. The segregation of atoms of $\mathrm{P}$ to the prior austenite grain boundaries (a factor already known in several processes of intergranular embrittlement) and the formation of cementite $\left(\mathrm{Fe}_{3} \mathrm{C}\right)$ around prior austenite grains are noticeable characteristics of $\mathrm{QE}^{4}$.

The literature has a tendency towards the basic supposition that the impact toughness of hardened steels increases as the tempering temperature increases, while, at the same time, the martensite decomposition increases gradually. Thus, the minimum toughness observed may be referred to tempered martensite embrittlement (TME), which may also be identified as "irreversible embrittlement", "one-step tempering embrittlement" or even as "embrittlement at $350{ }^{\circ} \mathrm{C} "$. In the case of high-strength steels, TME is characterized by a significant drop in the impact toughness values in temperatures between $200-370{ }^{\circ} \mathrm{C}^{[2]}$. Researchers have showed that as larger is the drop in impact toughness value (V-notch Charpy impact) in this interval of temperature, higher is the TME embrittlement severity. TME occurs in a tempering interval where the $\varepsilon$-carbides turn into cementite $\left(\mathrm{Fe}_{3} \mathrm{C}\right)$ and it mainly takes place in tempered martensitic microstructure. However, it is known that the same is likely to occur in steels with a bainite microstructure ${ }^{6}$.

Another type of embrittlement is the tempering embrittlement (TE), which is a metallurgical problem found in alloy steels containing certain impurities, such as phosphorus $(\mathrm{P})$, tin $(\mathrm{Sn})$, antimony $(\mathrm{Sb})$, and arsenic $(\mathrm{As})^{7}$. These elements cause embrittlement in the mentioned steel, tempered in the temperature range of $350-570{ }^{\circ} \mathrm{C}$, or during the low cooling rate during quenching in this temperature range. The embrittlement degree of steels depends on the impurity degree and the time in which it is kept in this temperature range. The impurities migrate to the grain boundaries during tempering period in the TE range. Relatively small amounts of these elements, as lower as $100 \mathrm{ppm}$ or less have been reported as the cause for $\mathrm{TE}^{2}$. Other elements are also cited as embrittling agents of TE: silicon $(\mathrm{Si})$, germanium $(\mathrm{Ge})$, selenium (Se), tellurium (Te) and bismuth (Bi). Manganese (Mn) content may cause both, TME and TE, and 
only carbon steels containing less than $0.3 \% \mathrm{Mn}$ are not considered susceptible to these embrittlements. $\mathrm{Ni}-\mathrm{Cr}$ steels are prone to TE, but the addition of molybdenum (Mo) in amounts of until $0.5 \%$ reduces its susceptibility to TE, therefore Mo becomes an important alloy element added to steels to minimize the chances of TE occurrence ${ }^{2}$. The TE phenomenon can also be named "reversible embrittlement" and "two-step embrittlement".

The map in Figure 1 defines the regions of intergranular and transgranular fractures, according to $\mathrm{C}$ and $\mathrm{P}$ contents for martensitic steels tempered at low temperatures, showing that the $\mathrm{C}$ content necessary to cause intergranular fracture, decreases as the $\mathrm{P}$ content increases $^{8}$. The effect of the $\mathrm{P}$ content, has been shown as a result of some research that prove that the $\mathrm{P}$ diminish the $\mathrm{C}$ solubility in the previous austenite, promoting in this way, the cementite formation at the prior austenite grain boundaries.

The fact that QE being uniformly developed in steels, even if they present low $\mathrm{P}$ contents (lower than $0.010 \mathrm{wt}$. (\%)), the rule states that the carbides formation in the grains boundaries carbides during $\mathrm{QE}$, is intrinsic to this phenomenon?.

Hyde ${ }^{10}$ showed that the embrittlement of quenched and tempered steels may lead to a reduction in the fatigue and endurance limits due to the segregation of $\mathrm{P}$ and/or cementite formation in the prior austenite grains boundaries. It has been observed that in superficially hardened steels susceptible to intergranular fracture, which is the case of carburized steels, the flexural fatigue may lead to crack nucleation, with size varying from two to four grains in depth, which grows steadily in an elliptical way until the critical size be reached and the final fracture occurs instantaneously. In these cases, the nucleation was correlated to the cementite formation at the prior austenite grains boundaries, leading to a reduction in the fatigue life by reducing the nucleation stage. Figure 2 illustrate this phenomenon, where a small intergranular fracture zone occurred during the nucleation of a fatigue crack. By analyzing two cemented steels, whose carbon content in the surface was about 1 wt. (\%) and P contents were 0.017 and 0.031 wt. (\%). Hyde observed that the fatigue strength had been changed, so the embrittlement affected more significantly the fatigue limit (Figure 3).

The quenching of high-strength steels to obtain harder martensitic structures is generally expected for high cycle fatigue regime and high wear performance. Nevertheless, this process can introduce microcracking and/or promote intergranular cracking nucleation at the grain boundaries ${ }^{10-12}$. In a brittle material, the strength of the grains is usually weaker than its interface, therefore cracks nucleate in transgranular way. Even so, with increasing hardening, the strength in the interior of a grain, usually becomes higher than at the interface (boundary), nucleating cracks intergranularly. Corresponding to this mechanism is the intergranular cracking by fatigue in low-carbon martensitic steels, where the proeutectoid ferrite precipitates at the prior austenite grains boundaries, weakening them ${ }^{13}$. In the case of carburized high-resistance steels, a flaw may occur intergranularly at the prior austenite grains boundaries, depending on the severity of the embrittlement ${ }^{14}$.

\section{Experimental}

\subsection{Material}

The material investigated in the present work was a SAE 5160 steel, with four different $\mathrm{P}$ content and provided as laminated bars with $70 \times 10 \mathrm{~mm}^{2}$ thickness and $1000 \mathrm{~mm}$ length. Its chemical composition is presented in Table 1 .

\subsection{Heat treatments}

Figure 4 presents a schematic flowchart indicating the heating treatments performed in the SAE 5160 steel bars, from which

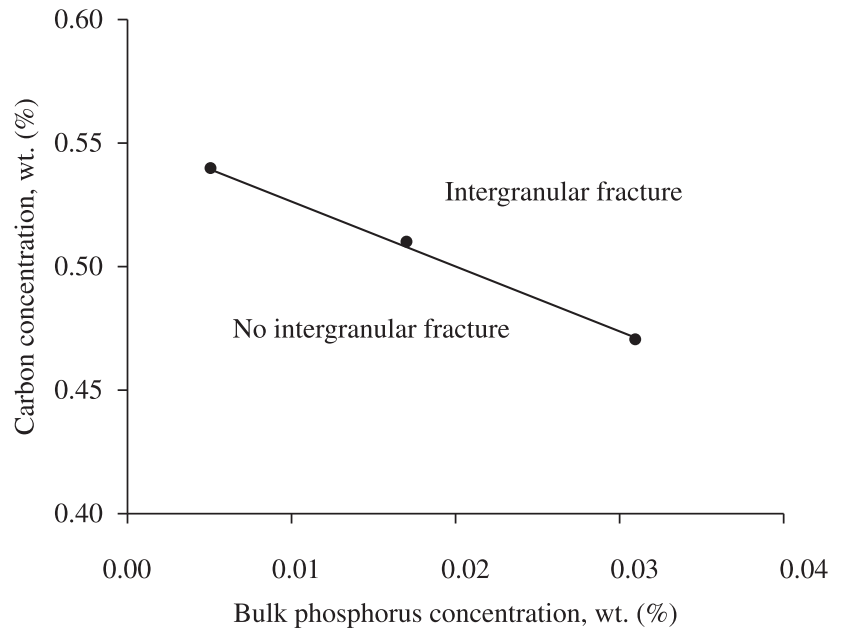

Figure 1. Fracture mode due to $\mathrm{P}$ and $\mathrm{C}$ contents for martensite tempered at low temperatures ${ }^{8}$.

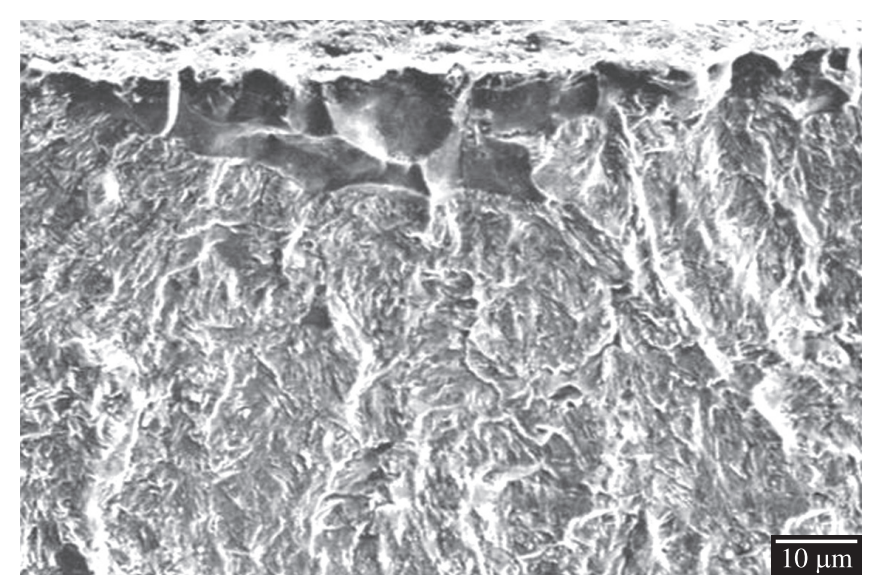

Figure 2. Location of the intergranular initiation of a fatigue fracture surface of a specimen of SAE 4320 carburized steel ${ }^{10}$.

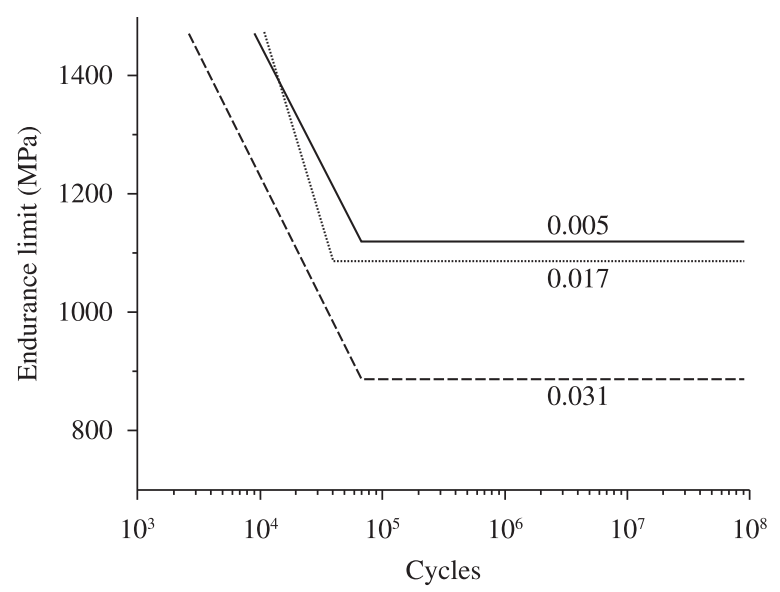

Figure 3. Comparison of maximum stress versus number of cycles for steels with different phosphorus contents ${ }^{10}$.

specimens were removed for hardness, impact toughness and fatigue (S-N) tests. These bars were gradually heated in a continuous two-heating zone furnace. The soaking time at the second zone was 15 minutes. All bars, after austenitizing, were quenched in mineral 
oil and tempered. Basically, three different austenitizing temperatures and three different tempering temperatures were studied for the four different levels of phosphorus studied. The quenching oil was always kept at $66{ }^{\circ} \mathrm{C}$.

\subsection{Mechanical tests}

As mentioned before, the hardness, impact, fracture toughness and fatigue (S-N) tests were performed to investigate the susceptibility of the SAE 5160, with different allowable P content, to the embrittlement effect, identifying the more adequate process parameters, as quenching and tempering temperatures, to avoid these embrittlements.

Rockwell C hardness tests were conducted in a Leco RT-240 $150 \mathrm{kgf}$ durometer using a $10 \mathrm{~mm}$ diameter conic penetrator $\left(120^{\circ}\right)$ made from diamond, according to ASTM E18-04. The hardness values represent an average of 10 measurements, acquired in the width of the surface in each sample.

For the impact tests, type A Charpy samples with V-notch were machined according to ASTM E23-04, as shown in Figure 5. The fabrication was performed in a milling machine and the $\mathrm{V}$-notch in a special backed-off cutter machine. The test specimens were removed in the L-S direction, so that the notch was parallel to the width of the sheet steel. This is the preferred direction for the in-service crack propagation. The tests were performed in an Instron Wolpert PW30 impact test device, using a $300 \mathrm{~J}$ maximum energy capacity and impact speed of $5.54 \mathrm{~m} / \mathrm{s}$.

The fatigue tests were performed in a 1 ton nominal capacity Guttman Eccentric Press (used for fatigue tests of flat springs). This machine uses a three-point bend device in which the specimen is placed over two points separated by $650 \mathrm{~mm}$ span, as shown in Figure 6. The maximum load applied was $1093 \mathrm{kN}$ (corresponding to a maximum tension stress of $\sigma_{\text {máx }}=130 \mathrm{MPa}$ in the center of the bar at surface), which corresponds to a load necessary to cause a $25 \mathrm{~mm}$ deflection in the center of the bar. It is important to mention that all specimens, underwent to a shot-peening process on the surface that

Table 1. Chemical composition of SAE 5160 steel wt. (\%).

\begin{tabular}{cccccc}
\hline & $\begin{array}{c}\text { Specification } \\
\text { SAE }\end{array}$ & Steel A & Steel B & Steel C & Steel D \\
\hline $\mathrm{C}$ & $0.56-0.64$ & 0.593 & 0.580 & 0.584 & 0.600 \\
$\mathrm{Mn}$ & $0.75-1.00$ & 0.860 & 0.850 & 0.850 & 0.860 \\
$\mathrm{P}$ & 0.030 (máx) & 0.012 & 0.017 & 0.025 & 0.031 \\
$\mathrm{~S}$ & 0.035 (máx) & 0.012 & 0.011 & 0.008 & 0.005 \\
$\mathrm{Si}$ & $0.15-0.35$ & 0.250 & 0.230 & 0.012 & 0.190 \\
$\mathrm{Cr}$ & $0.70-0.90$ & 0.800 & 0.770 & 0.780 & 0.770 \\
$\mathrm{Ni}$ & $0.00-0.25$ & 0.070 & 0.090 & 0.070 & 0.090 \\
\hline
\end{tabular}

during test would be under tensile stresses, before they were fatiguetested, similarly to the procedure for regular leaf springs.

The three points fracture toughness tests were performed according to ASTM E1820-06. The load ratio, maximum load and frequency used in the fatigue pre-cracking of specimens were, $\mathrm{R}=0.1$, $\mathrm{P}_{\text {máx }}=5.5 \mathrm{kN}$ and $\mathrm{f}=30 \mathrm{~Hz}$, respectively.

A servo-hydraulic MTS810 system was used to conduct the fracture toughness test. As the bar thickness was only $10 \mathrm{~mm}$, the specimens was removed in the T-L direction and three-point bend specimens, $\mathrm{SE}(\mathrm{B})$ were used with $\mathrm{B}=10 \mathrm{~mm} ; \mathrm{W}=20 \mathrm{~mm} ; \mathrm{a}_{0}=9.5$; $\mathrm{S}_{\mathrm{d}}=80 \mathrm{~mm}$; and $\mathrm{f}(\mathrm{a} / \mathrm{W})=2.46$, as shown in Figure 7 . The rate of applied load was $13 \mathrm{kN} / \mathrm{min}$ and the crack opening displacement was measured using an extensometer fixed at the crack mouth.

Initially, two alloys were previously chosen in an attempt to validate the obtained $\mathrm{K}_{\mathrm{IC}}$ values. The criterion was the selection of specimens heat treated for the more fragile and more ductile conditions. For validation purpose, it is worthwhile to emphasize that the blade gage restricted the specimen to its thickness $(\mathrm{B})=10 \mathrm{~mm}$.

As stated by the ASTM 1820-06 standard, the condition that must be satisfied is:

$$
a, B,(W-a) \geq 2,5\left(\frac{K_{I C}}{\sigma_{e}}\right)^{2}
$$

\subsection{Grain size analysis}

Samples removed from the bars were prepared according to ASTM E3-08. After the surface preparation, a chemical attack

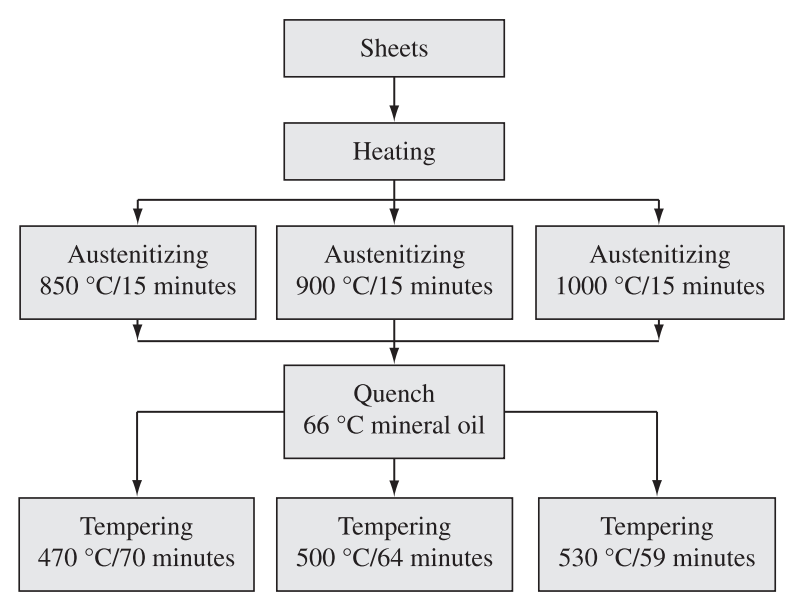

Figure 4. Schematic flowchart of the heating treatment routs for the SAE 5160 steel bars.
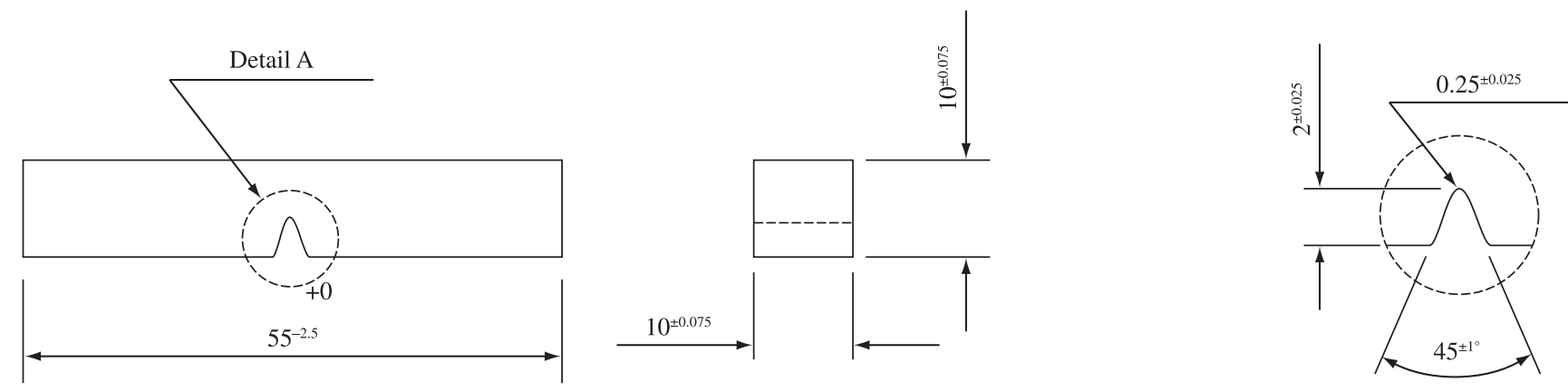

Figure 5. Size and geometry of the type A Charpy specimens according to ASTM E23-04. 
was performed on the surface of each sample. The chemical attack consisted in a solution of $1.0 \mathrm{~g}$ of picric acid, $1.0 \mathrm{~mL}$ of chloride acid, $15.0 \mathrm{~mL}$ of detergent $+100.0 \mathrm{~mL}$ of distilled water, over a time of six minutes. Afterwards, each sample was observed in a Zeiss Axiotech Stemi DV4/DR microscope connected to Graftek Ultimage Optlab

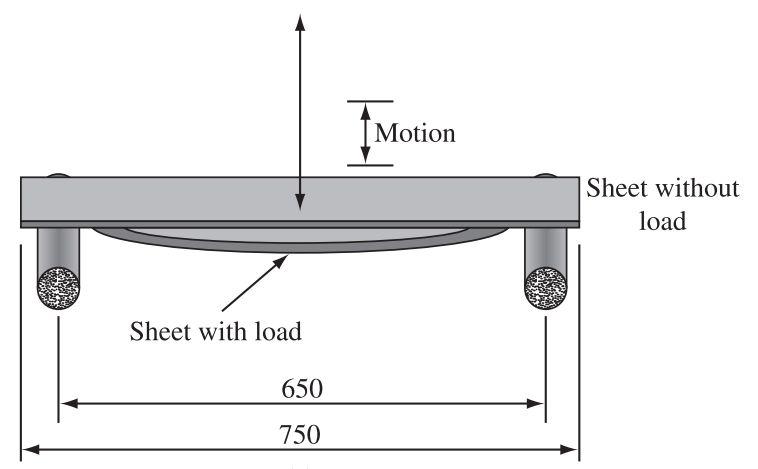

(a)

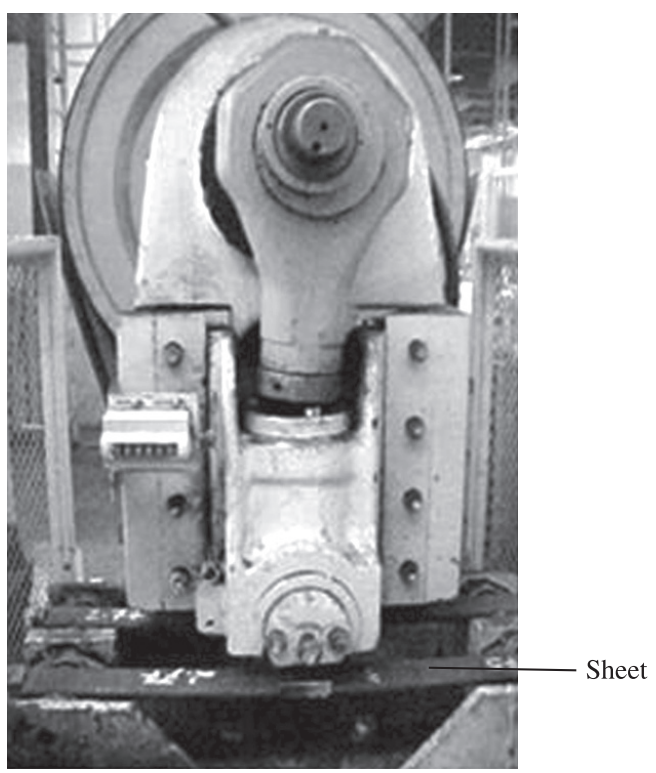

(b)

Figure 6. Schematic representation of the fatigue test. The dimensions are in $\mathrm{mm}$. software, Version 2.6. The grain size was measured according to ASTM E-1382-04.

\subsection{Fractographic analysis}

The fracture surface of the broken specimens after impact, fracture toughness and fatigue tests, were observed in a DSM 960 ZE155 scanning electronic microscope. The fracture surfaces have been previously cleaned with acetone in an ultrasonic equipment, so that no undesirable impurity would influence the analysis. This type of analysis is required to evaluate the micro-mechanism of fractures.

\section{Results and Discussion}

As observed in Table 1, except for the P content, the chemical compositions of the four steels are alike. The $\mathrm{P}$ content was below the maximum allowable value always.

Table 2 shows the values of grain sizes for each condition. The invariability of the grain size was expected since these steels were aluminum killed to avoid large grains.

Figure 8 shows the mean hardness values obtained from each steel composition and heat treatment as presented in the flow chart in Figure 4. For the same austenitizing temperature, the hardness values decrease for an increasing tempering temperature, However, it is seen that the dependence on tempering temperature is reduced as the austenitizing temperature for quenched increased from 850 to $1000{ }^{\circ} \mathrm{C}$. Most hardness values of the tested samples are inside the limits specified for the leaf springs produced from this steel, i.e., 43-48 HRC. For the steel D $\left(0.031 \%\right.$ of P) tempered at $530{ }^{\circ} \mathrm{C}$, the hardness value was slightly below the minimum value (43 HRC). These lower hardness values produced higher impact energy values than those expected for the SAE heat treated for the nominal hardness value (43-48 HRC). Unfortunately, at the highest tempering temperature $\left(530{ }^{\circ} \mathrm{C}\right)$, the furnace did not allowed further reduction in the time range (due to speed of stretching of the oven) to provide the necessary hardness value.

Figure 9 shows an overall representation of the absorbed impact energy for all heat treatment conditions, considering the different levels of $\mathrm{P}$ investigated. It is observed that, independent of the austenitizing temperature for quenching, lower the P content, higher were the values of absorbed impact energy, especially for the tempering temperature of $500{ }^{\circ} \mathrm{C}$. Also, steel A $(0.012 \mathrm{P})$ austenitized at $850{ }^{\circ} \mathrm{C}$ and tempered at $500{ }^{\circ} \mathrm{C}$ exhibited the highest value of absorbed impact energy, approximately $400 \mathrm{~kJ} . \mathrm{m}^{-2}$, despite its highest
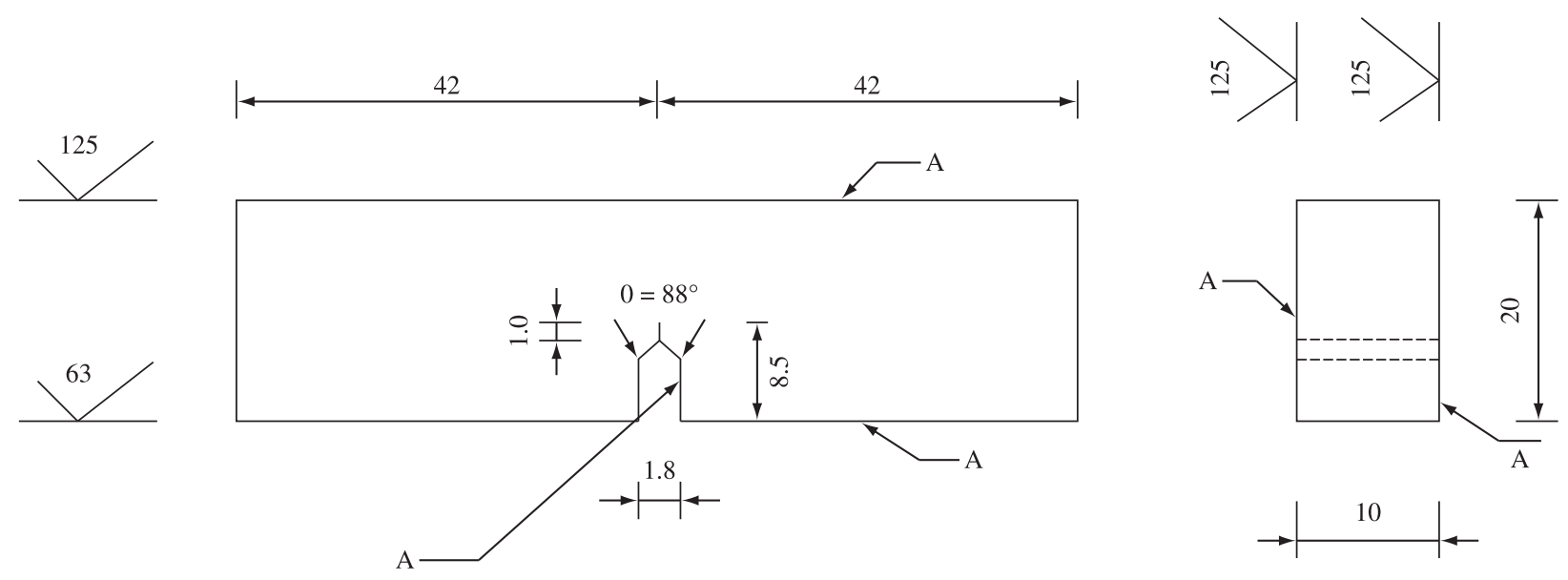

Figure 7. SE (B) specimen dimensions and geometry used for fracture toughness tests. Dimensions are in mm. 
Table 2. Grain size ASTM $(\mu \mathrm{m})$ for each studied condition.

\begin{tabular}{|c|c|c|c|c|}
\hline \multirow{2}{*}{\multicolumn{2}{|c|}{ Steel A $(0.012 \%$ P $)$}} & \multicolumn{3}{|c|}{$\mathrm{T}_{\text {tempering }}$} \\
\hline & & $470^{\circ} \mathrm{C}$ & $500^{\circ} \mathrm{C}$ & $530^{\circ} \mathrm{C}$ \\
\hline \multirow{3}{*}{$\mathrm{T}_{\text {quenching }}$} & $850{ }^{\circ} \mathrm{C}$ & --- & $24.4 \pm 0.1$ & --- \\
\hline & $900{ }^{\circ} \mathrm{C}$ & --- & $25.0 \pm 0.3$ & --- \\
\hline & $1000^{\circ} \mathrm{C}$ & --- & $23.9 \pm 0.3$ & --- \\
\hline \multirow{2}{*}{\multicolumn{2}{|c|}{ Steel B $(0.017 \%$ P) }} & \multicolumn{3}{|c|}{$\mathrm{T}_{\text {tempering }}$} \\
\hline & & $470{ }^{\circ} \mathrm{C}$ & $500^{\circ} \mathrm{C}$ & $530^{\circ} \mathrm{C}$ \\
\hline \multirow{3}{*}{$\mathrm{T}_{\text {quenching }}$} & $850^{\circ} \mathrm{C}$ & $24.9 \pm 0.3$ & $24.3 \pm 0.4$ & $25.0 \pm 0.1$ \\
\hline & $900^{\circ} \mathrm{C}$ & $24.1 \pm 0.2$ & $23.5 \pm 0.1$ & $24.0 \pm 0.1$ \\
\hline & $1000^{\circ} \mathrm{C}$ & $23.0 \pm 0.1$ & $22.9 \pm 0.1$ & $22.8 \pm 0.3$ \\
\hline \multirow{2}{*}{\multicolumn{2}{|c|}{ Steel C $(0.025 \%$ P) }} & \multicolumn{3}{|c|}{$\mathrm{T}_{\text {tempering }}$} \\
\hline & & $470{ }^{\circ} \mathrm{C}$ & $500{ }^{\circ} \mathrm{C}$ & $530^{\circ} \mathrm{C}$ \\
\hline \multirow{3}{*}{$\mathrm{T}_{\text {quenching }}$} & $850^{\circ} \mathrm{C}$ & --- & $24.9 \pm 0.3$ & --- \\
\hline & $900{ }^{\circ} \mathrm{C}$ & --- & $24.4 \pm 0.2$ & --- \\
\hline & $1000^{\circ} \mathrm{C}$ & --- & $23.8 \pm 0.2$ & --- \\
\hline \multirow{2}{*}{\multicolumn{2}{|c|}{ Steel D $(0.031 \%$ P $)$}} & \multicolumn{3}{|c|}{$\mathrm{T}_{\text {tempering }}$} \\
\hline & & $470{ }^{\circ} \mathrm{C}$ & $500{ }^{\circ} \mathrm{C}$ & $530^{\circ} \mathrm{C}$ \\
\hline \multirow{3}{*}{$\mathrm{T}_{\text {quenching }}$} & $850{ }^{\circ} \mathrm{C}$ & $24.7 \pm 0.1$ & $24.2 \pm 0.2$ & $23.6 \pm 0.1$ \\
\hline & $900{ }^{\circ} \mathrm{C}$ & $25.0 \pm 0.1$ & $23.7 \pm 0.2$ & $24.1 \pm 0.2$ \\
\hline & $1000^{\circ} \mathrm{C}$ & $22.8 \pm 0.2$ & $23.2 \pm 0.2$ & $22.5 \pm 0.2$ \\
\hline
\end{tabular}

Obs: --- means that no measurement was made.

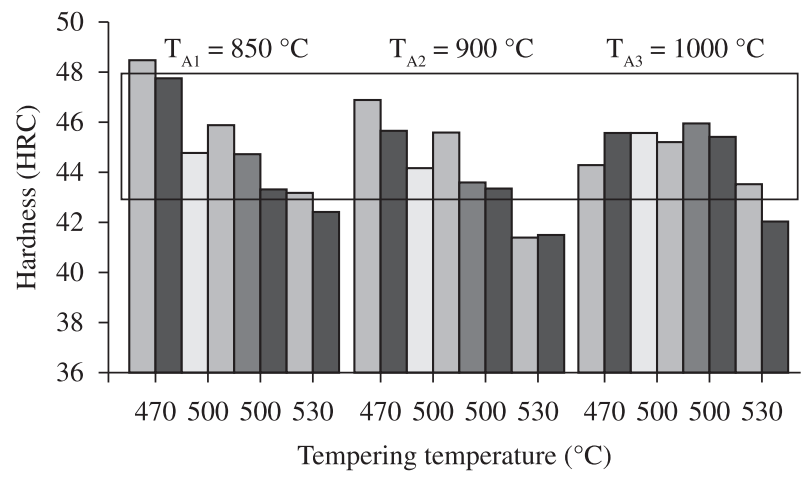

$\square$ Alloy A $(0.012 \%$ P) $\square$ Alloy B $(0.017 \%$ P)

$\square$ Alloy C $(0.025 \%$ P $) \square$ Alloy D $(0.031 \% \mathrm{P})$

Figure 8. Hardness test results versus tempering temperature for three austenitizing temperatures $\left(\mathrm{TA}_{1}, \mathrm{TA}_{2}\right.$, and $\left.\mathrm{TA}_{3}\right)$.

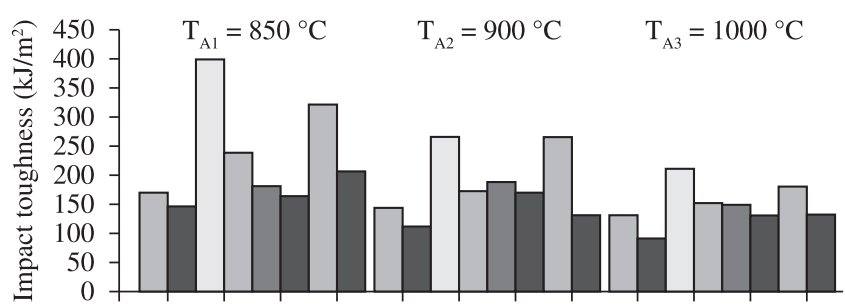

$470500500530 \quad 470 \quad 500 \quad 500 \quad 530 \quad 470 \quad 500 \quad 500 \quad 530$

Tempering temperature $\left({ }^{\circ} \mathrm{C}\right)$

$\square$ Alloy A $(0.012 \%$ P $) \quad \square$ Alloy B $(0.017 \%$ P $)$

$\square$ Alloy C $(0.025 \% \mathrm{P}) \quad \square$ Alloy $\mathrm{D}(0.031 \% \mathrm{P})$

Figure 9. Absorbed energy in the Charpy impact test. Comparative image for all conditions studied in this work. hardness values when compared to the ones obtained at austenitizing temperature of $900{ }^{\circ} \mathrm{C}$.

According to Reguly ${ }^{4}$, for the SAE 5160 steel an increase in the tempering temperature, will cause an improvement on the impact toughness, if the phosphorus content is low $(0.001 \mathrm{wt} .(\%))$, since it will not develop quench embrittlement. In the case that the P content was low, but developed quench embrittlement after austenitizing at $1100{ }^{\circ} \mathrm{C}$, there was an improvement in the impact toughness when the tempering temperature was high. Reguly ${ }^{4}$, observed also that improvement in the impact toughness values were obtained when the austenitizing temperature was below $1100^{\circ} \mathrm{C}$.

As mentioned before, the hardness values of any specimen tempered at $530{ }^{\circ} \mathrm{C}$ were not in the required hardness interval (43-48 HRC), as a consequence the toughness values were overestimated and the fracture surfaces of these specimens were not considered for the analyses in this article.

Figure 10 shows the fractographic images of the Charpy impact specimens tempered at $470{ }^{\circ} \mathrm{C}$ for 70 minutes. For Steel $\mathrm{D}(0.031 \mathrm{wt} .(\%) \mathrm{P})$ the intergranular fracture prevails at all austenitizing temperatures, while the intergranular fracture of steel B (0.017 wt. (\%) P) occurs only for austenitizing at $1000{ }^{\circ} \mathrm{C}$. The austenitizing temperatures of 850 and $900{ }^{\circ} \mathrm{C}$ for steel $\mathrm{B}(0.017 \mathrm{P})$ produced a region of mixed fracture (ductile + intergranular) with a dominance of ductile type. The amount of intergranular fracture gradually increases as the austenitizing temperature rises, explaining the gradual drop in the impact toughness values, according to the increase in the austenitizing temperature for both steels B and D for the studied steels, Figure 9.

Figures 11 and 12 show images of impact specimens tempered at $500{ }^{\circ} \mathrm{C}$ for 64 minutes. In steels A (0.012 wt. (\%) P) and $\mathrm{C}$ (0.025 wt. (\%) P). Figure 12 features a ductile fracture of steel B (0.017 wt. (\%) P) and also a mixed aspect in the specimen from steel D (0.031 wt. (\%) P), which shows mostly ductile with only some regions of intergranular fracture. This intergranular portion is directly connected to the $33 \%$ decrease in the impact toughness if compared to specimens from steel B $(0.017 \mathrm{wt}$. (\%) P), which display an absorbed impact energy of $240.54 \mathrm{~kJ} . \mathrm{m}^{-2}$.

Thus, for the austenitizing temperature of $850{ }^{\circ} \mathrm{C}$ it is clearly noticed that increasing the $\mathrm{P}$ content, the amount of intergranular fracture increased and consequently the value of the absorbed impact energy was reduced. Yet, for those cases of austenitizing temperature of $900{ }^{\circ} \mathrm{C}$, Figure 12 shows the predominance of intergranular fracture for specimens from steel D with high P content (0.031 wt. (\%)), and predominance of ductile fracture for specimens taken from steel B with medium $\mathrm{P}$ content $(0.017$ wt. $(\%))$. However, unexpectedly the impact toughness values of both steels were quite similar, i.e., 173 and $168 \mathrm{~kJ} . \mathrm{m}^{-2}$ for steels B and $\mathrm{D}$, respectively.

At austenitizing temperature of $1000^{\circ} \mathrm{C}$, steel B (0.017 wt. (\%) P) exhibited a significantly larger portion of intergranular fracture than the specimens austenitized at $900{ }^{\circ} \mathrm{C}$. Such fact is evidenced by the fall of approximately $13 \%$ in the value of impact toughness when the autenitizing temperature was $1000{ }^{\circ} \mathrm{C}$. On the other hand, the sample of steel D (0.031 wt. (\%) P) displayed a fracture surface with predominantly intergranular type.

In short, the fractographic analysis agrees the fact that the values of impact toughness of the steels with higher levels of phosphorus are always lower than those with lower levels of P (Figure 9). The large portion of intergranular fracture found in steels with higher levels of $\mathrm{P}$ is related to the decrease in the values of absorbed impact energy. It can be inferred that this embrittlement phenomenon is due to the segregation of phosphorus occurred during the respective austenitizing and/or tempering heat treatments, for steels with higher P content ${ }^{9}$. 


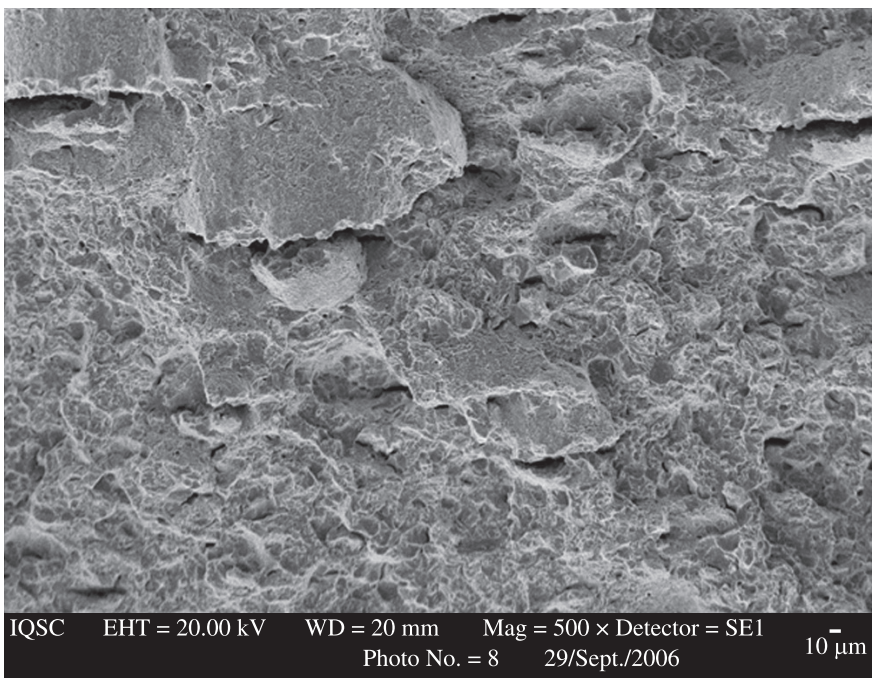

(a)

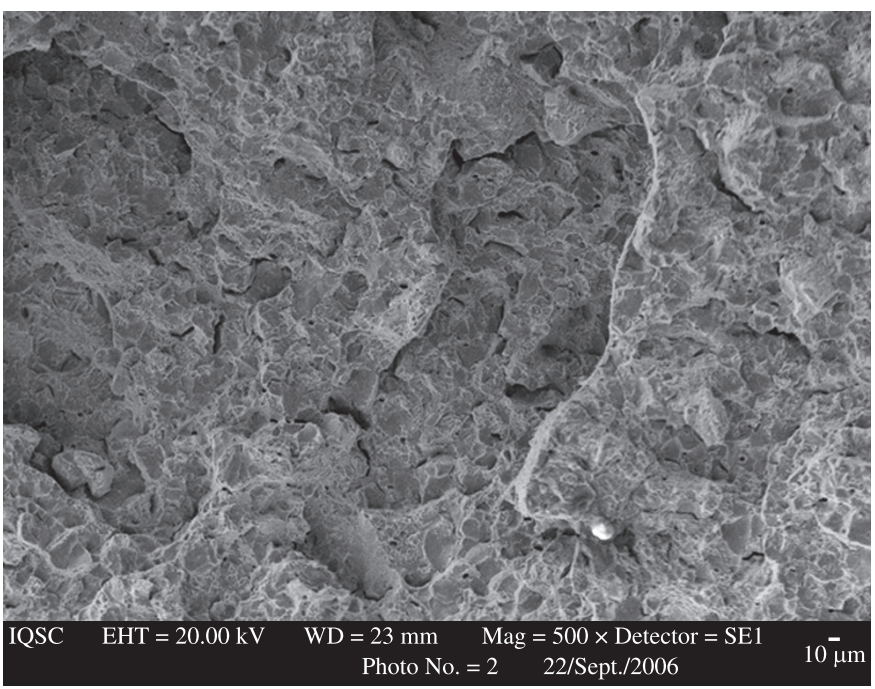

(c)

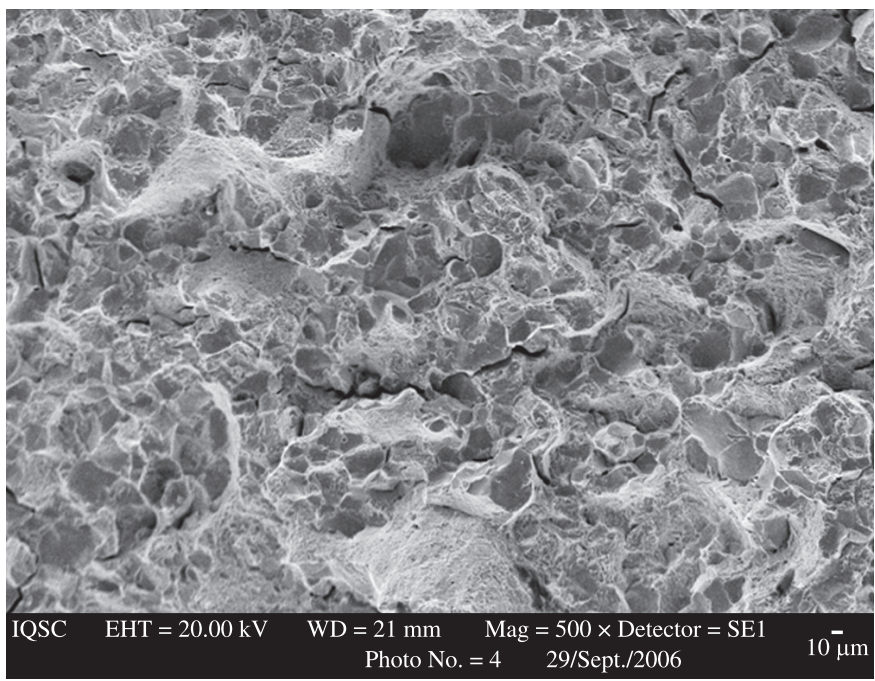

Figure 10. Fracture surface (central part of the fracture) of impact specimens. Steel with 0.017 wt. (\%) P (steel B) austenitized at: a) $850{ }^{\circ} \mathrm{C}$; c) $900{ }^{\circ} \mathrm{C}$; and e) $1000{ }^{\circ} \mathrm{C}$. Steel with $0.031 \mathrm{wt}$ ( \%) P (steel D) austenitized at: b) $850{ }^{\circ} \mathrm{C}$; d) $900{ }^{\circ} \mathrm{C}$; and f) $1000{ }^{\circ} \mathrm{C}$. The specimens were tempered at $470{ }^{\circ} \mathrm{C}$ for 70 minutes.

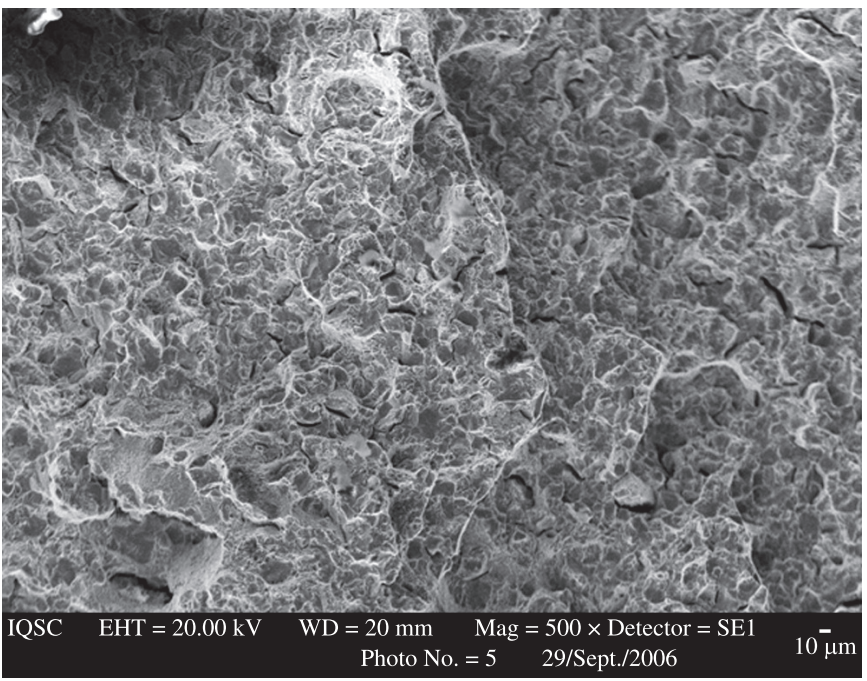

(b)

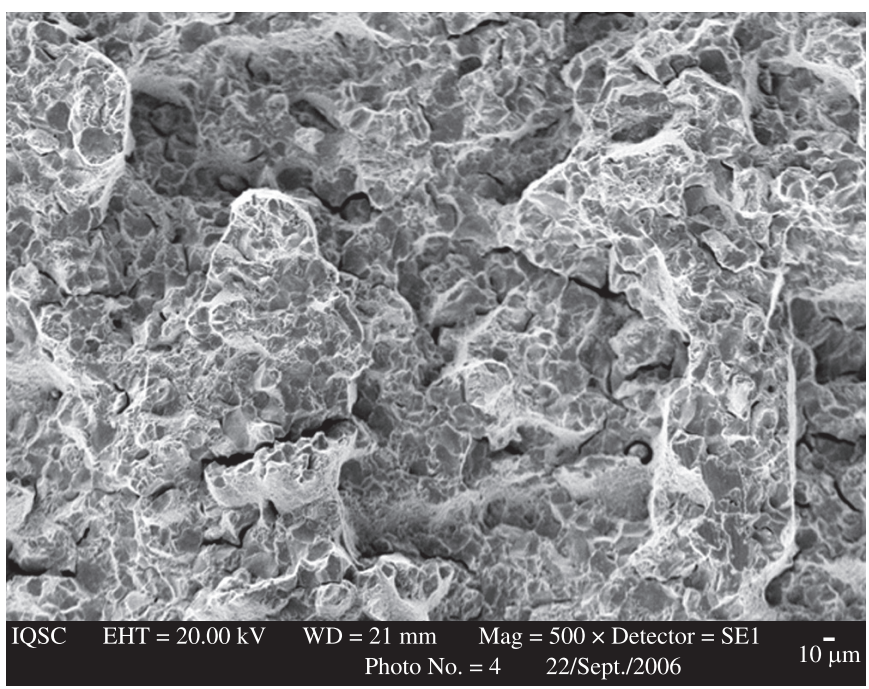

(d)

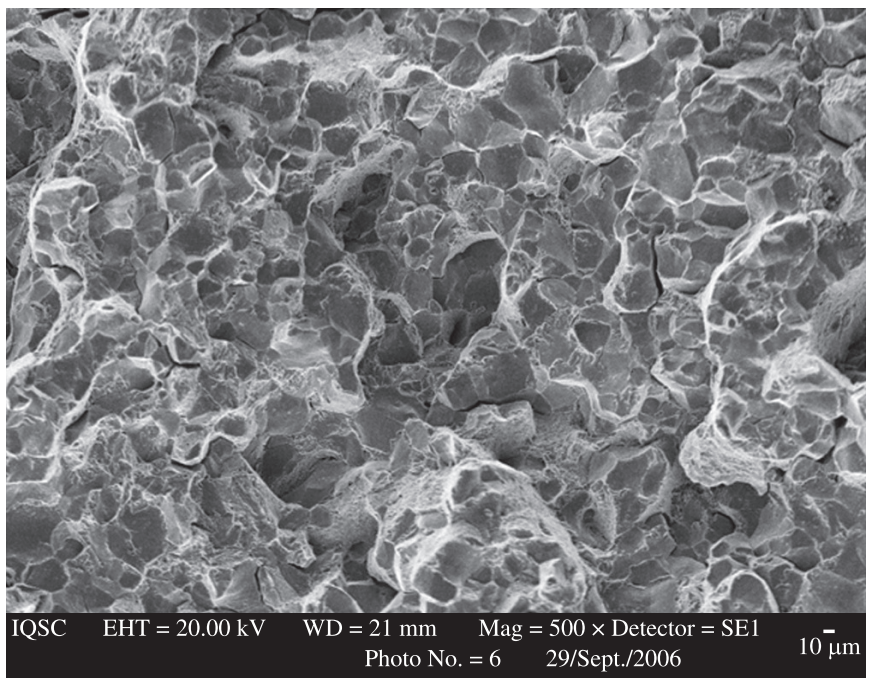




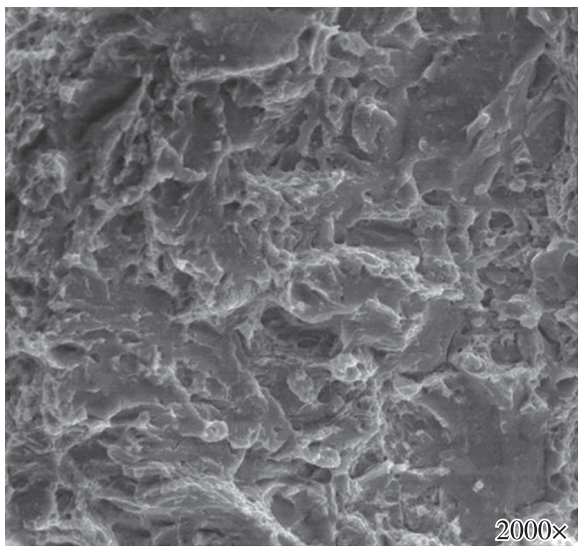

(a)

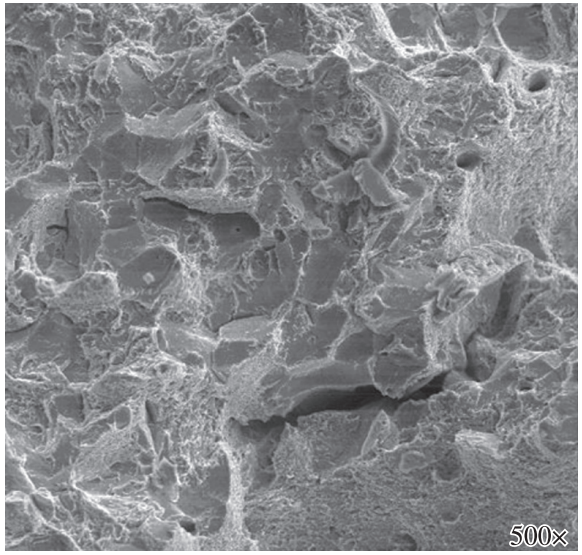

(d)

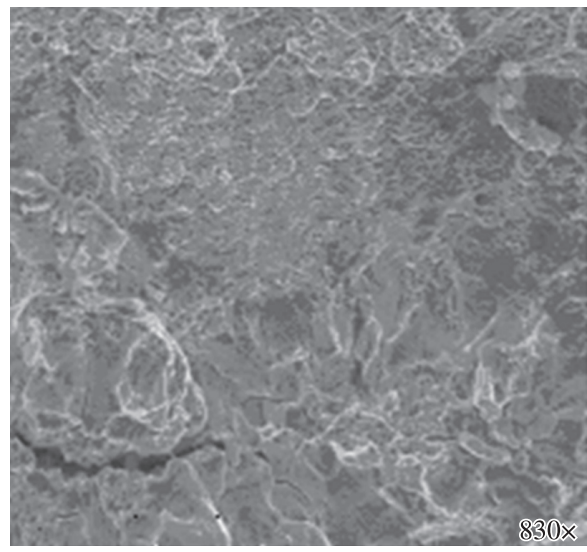

(b)

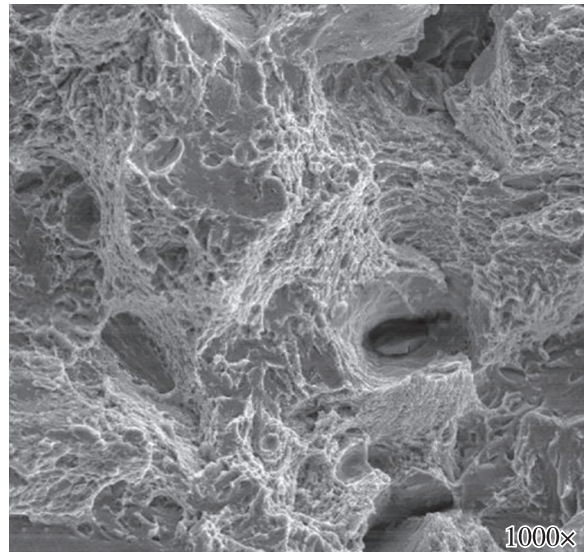

(e)

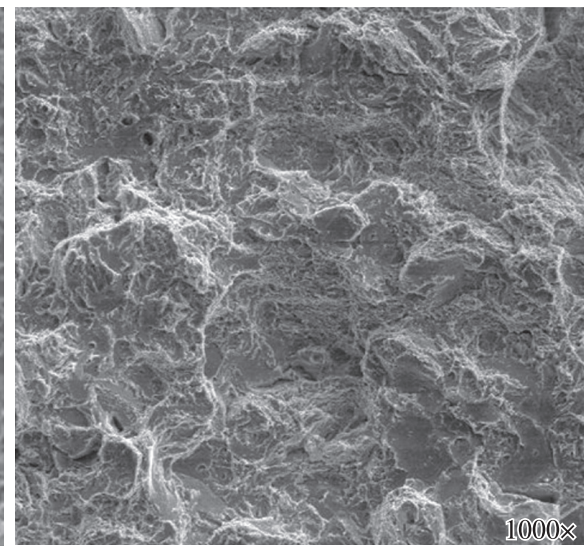

(c)

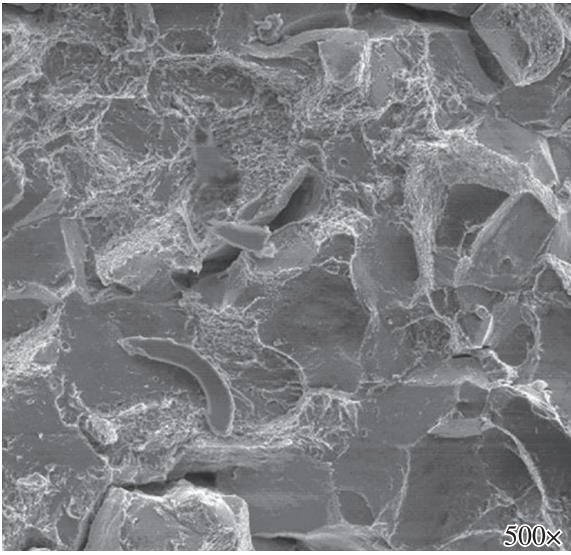

(f)

Figure 11. Fracture surface (central part of the fracture) of the impact specimens. Steel with 0.012 wt. (\%) P (steel A) austenitized at: a) $850{ }^{\circ} \mathrm{C}$; c) $900{ }^{\circ} \mathrm{C}$; and e) $1000{ }^{\circ} \mathrm{C}$. Steel with 0.025 wt. (\%) P (steel C) austenitized at: b) $850{ }^{\circ} \mathrm{C}$; d) $900{ }^{\circ} \mathrm{C}$; and f) $1000{ }^{\circ} \mathrm{C}$. The specimens were tempered at $500{ }^{\circ} \mathrm{C}$ for 64 minutes.

Figure 13a shows the Load versus COD curve for steel B (0.017 wt. (\%) P) austenitized at $850{ }^{\circ} \mathrm{C}$ and tempered at $530{ }^{\circ} \mathrm{C}$. According to ASTM E1820-2006, it is observed that the curve for steel $\mathrm{B}$ is from Type $\mathrm{I}$, meaning that the value of $\mathrm{P}_{\mathrm{Q}}$ is lower than the value of $\mathrm{P}_{\text {maxx }}$. Thus, it is necessary to use the procedure of the $5 \%$ secant line $\mathrm{OP}_{5}$. Figure $13 \mathrm{~b}$ shows the behavior of a steel D (0.031 wt. $(\%)$ of P) austenitized at $1000{ }^{\circ} \mathrm{C}$ and tempered at $470{ }^{\circ} \mathrm{C}$. The Load versus COD curve in this case is from type III, with elastic behavior an indicative of low toughness.

Table 3 shows the fracture toughness results for specimens from steel B (0.017 wt. (\%) of P) and steel D (0.031 wt. (\%) of P). The last line of Table 3 shows the results of a, (W-a) and B, which are the requirements for $\mathrm{K}_{\mathrm{Q}}$ be considered the fracture toughness value in plane strain state condition, $\mathrm{K}_{\mathrm{IC}}$. It is observed that $\mathrm{B}=10.0 \mathrm{~mm}$ did not allowed the obtaining of a valid value of $\mathrm{K}_{\mathrm{IC}}$ for steel $\mathrm{B}$ (austenitized at $850{ }^{\circ} \mathrm{C}$ and tempered at $530{ }^{\circ} \mathrm{C}$ ), therefore it is considered as $\mathrm{K}$ only. However, for steel D (austenitized at $1000^{\circ} \mathrm{C}$ and tempered at $470{ }^{\circ} \mathrm{C}$ ), it was possible to obtain $\mathrm{K}=\mathrm{K}_{\mathrm{IC}}$, therefore only the values of $\mathrm{K}_{Q}$ were used for toughness for these tested conditions. Note that, similarly to the impact test trend with $\mathrm{P}$ content, the values of $\mathrm{K}_{\mathrm{Q}}$ decreases as the phosphorus level increases.

The values of $K_{Q}$ relates well with the fracture surface results, i.e., steel $\mathrm{B}$, which had a higher value of $\mathrm{K}_{\mathrm{Q}}$, presented a ductile fracture mode, while steel $\mathrm{D}$, which had a lower value of $\mathrm{K}_{\mathrm{Q}}$, presented a brittle fracture mode. The fracture surface from steel B, Figure 14, shows a ductile fracture mode, with stable crack growth by coalescence of microvoids, Figure 14b. In this specimen it was also observed a delamination, where the internal faces presents a more brittle aspect, Figure 14c. From Figure 15 it is seen that steel D exhibited a more brittle mode of fracture, with a mixture of cleavage and intergranular types. Such a fracture micromechanism occurred due its highest $\mathrm{P}$ content, even considering that it is inside of the allowable range. As previously observed by other researchers ${ }^{9-11}$, atoms of $\mathrm{P}$ may migrate to prior austenitic grain boundaries, making the steel to behave in a brittle manner. However, it is not possible to precise in which step it has occurred, if during austenitizing or tempering.

Figure 16 presents the results of the fatigue tests. Note that, for similar heat treatment, there is a spread in the measured values of fatigue life. This scattering could be related to the stress concentrators in the spring surface and/or local changes in mechanical properties, considering that the specimens were directly acquired from bars made on industrial scale. However, besides the austenitizing and tempering temperatures, the values of high cycle fatigue life were not significantly affected by the embrittlement caused by a higher level of $\mathrm{P}$, as the heat treatments aimed to produce micro-structures able to provide similar mechanical properties, such as hardness and tensile strength to the specimens, consequently causing a similar high cycle fatigue life. 


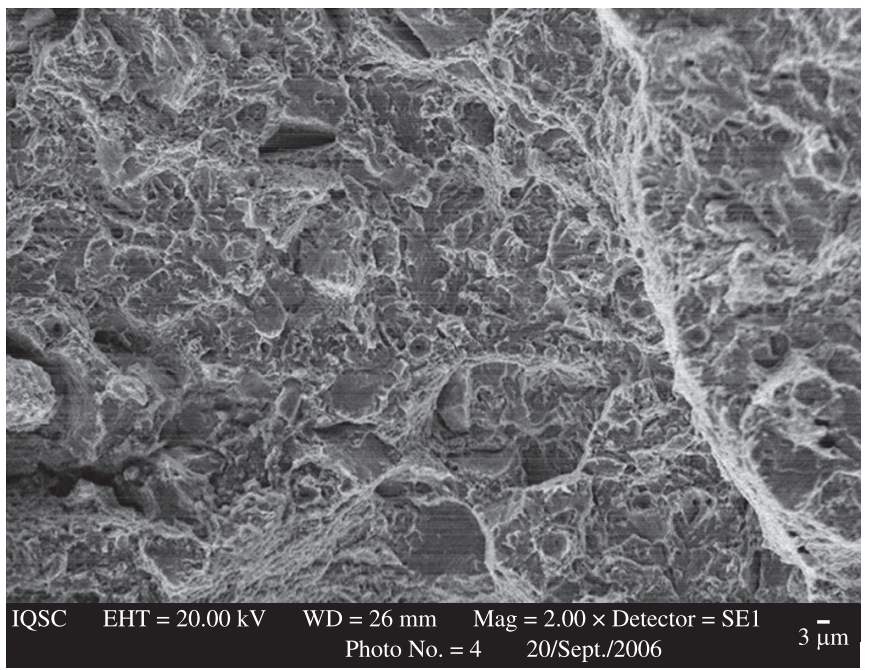

(a)

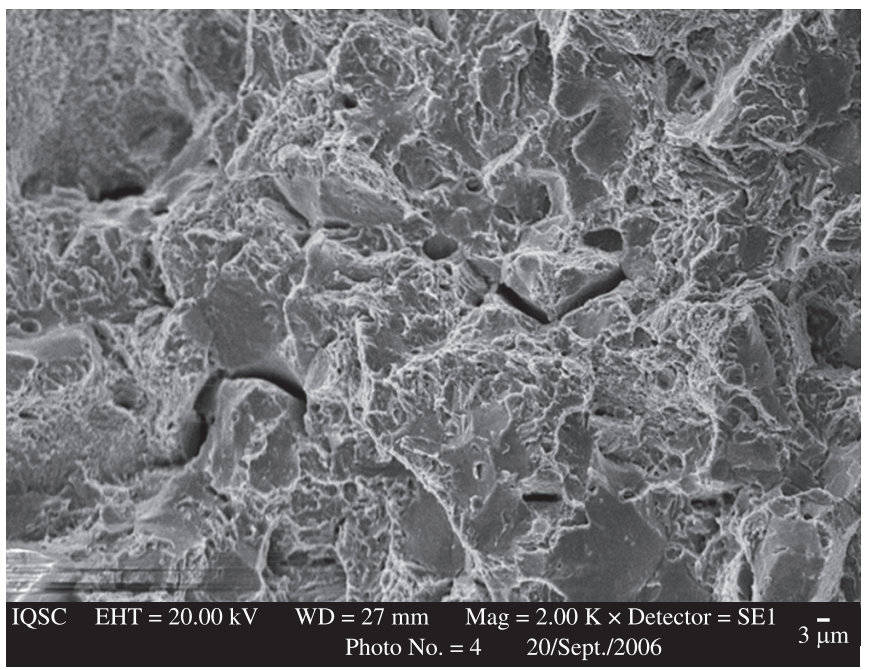

(c)

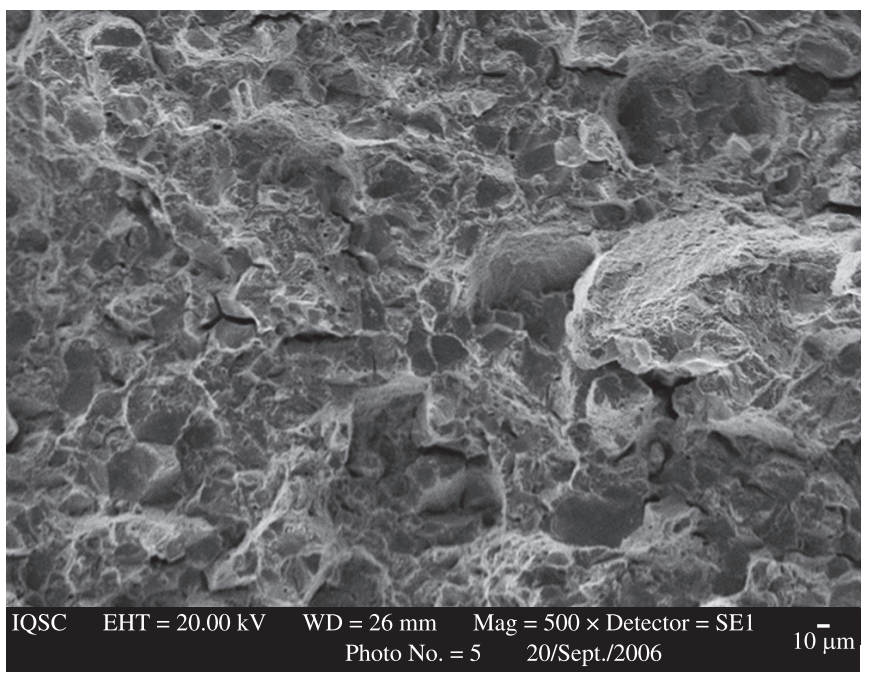

(e)

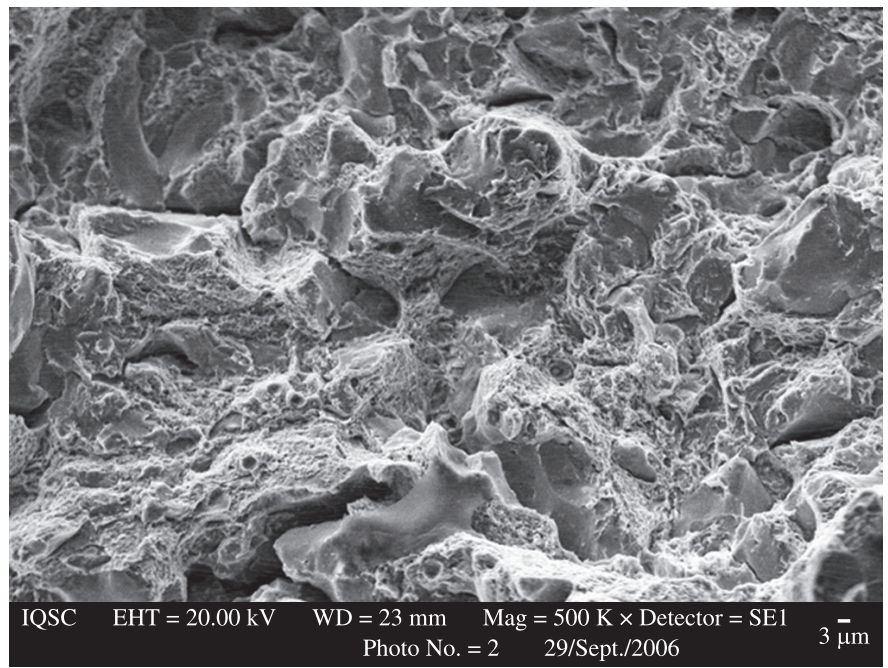

(b)

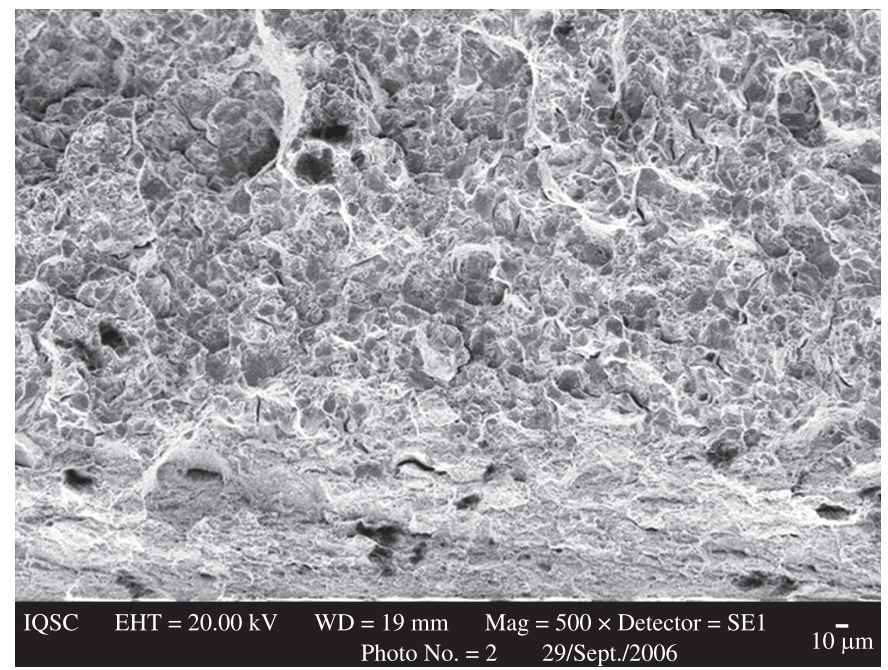

(d)

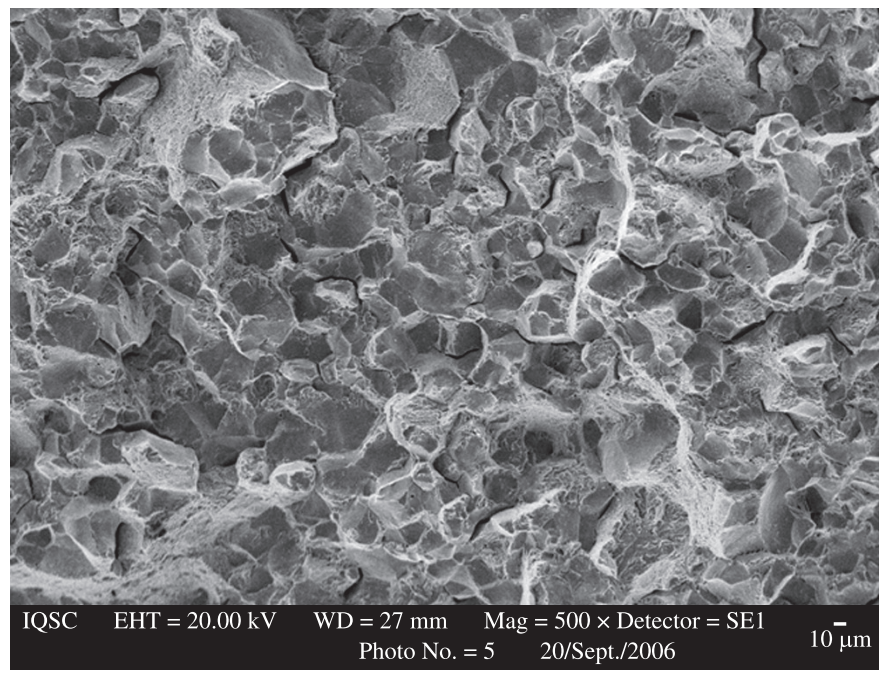

(f)

Figure 12. Fracture surface (central part of the fracture) of the impact specimens. Steels with 0.017 wt. $(\%) \mathrm{P}$ (steel B) austenitized at: a) $850{ }^{\circ} \mathrm{C}$; c) $900{ }^{\circ} \mathrm{C}$; and e) $1000{ }^{\circ} \mathrm{C}$. Steels with 0.031 wt. (\%) P (steel D) austenitized at: b) $850{ }^{\circ} \mathrm{C}$; d) $900{ }^{\circ} \mathrm{C}$; and f) $1000{ }^{\circ} \mathrm{C}$. The specimens were tempered at $500{ }^{\circ} \mathrm{C}$ for 64 minutes. 


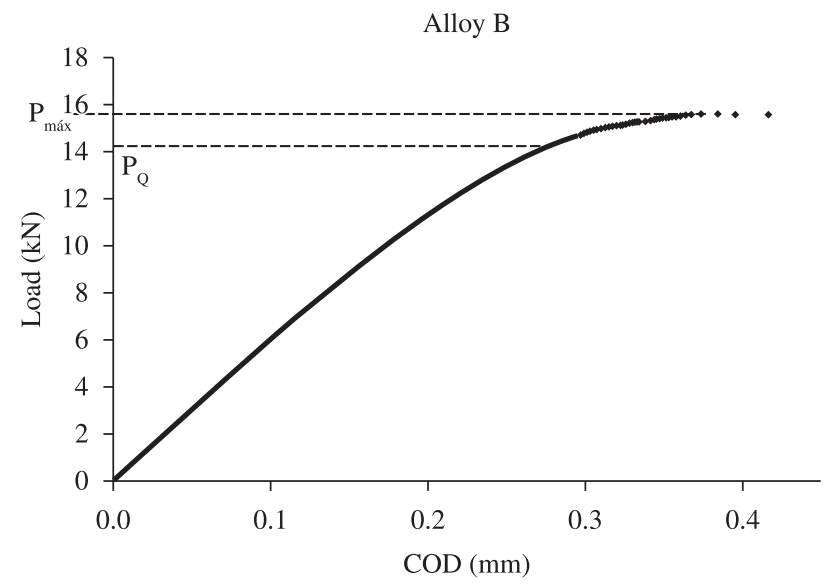

(a)

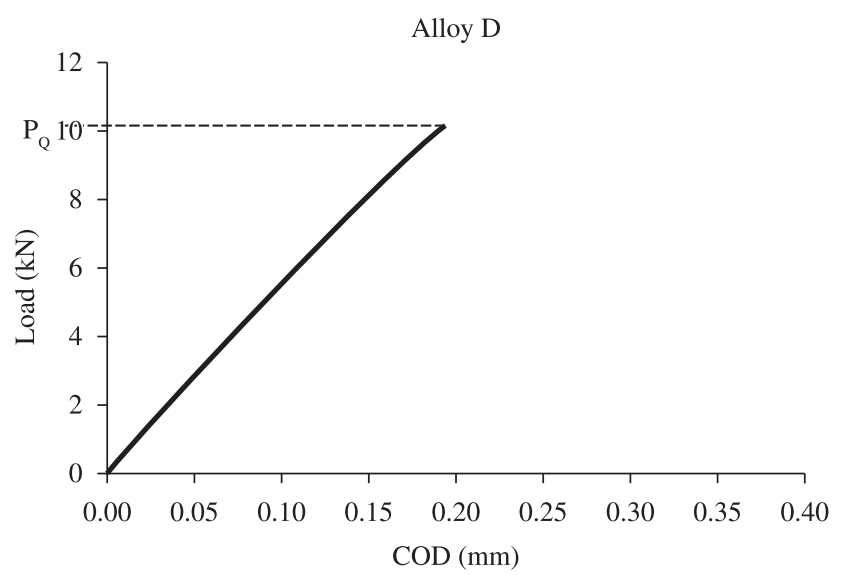

(b)

Figure 13. Load versus crack opening displacement form SEN(B) specimens for determination of KQ: a) steel B $(0.017$ wt. $(\%)$ of $\mathrm{P})$ austenitized at $850{ }^{\circ} \mathrm{C}$ and tempered at $530{ }^{\circ} \mathrm{C}$ and b) steel $\mathrm{D}\left(0.031\right.$ wt. $(\%)$ of P) austenitized at $1000{ }^{\circ} \mathrm{C}$ and tempered at $470{ }^{\circ} \mathrm{C}$.

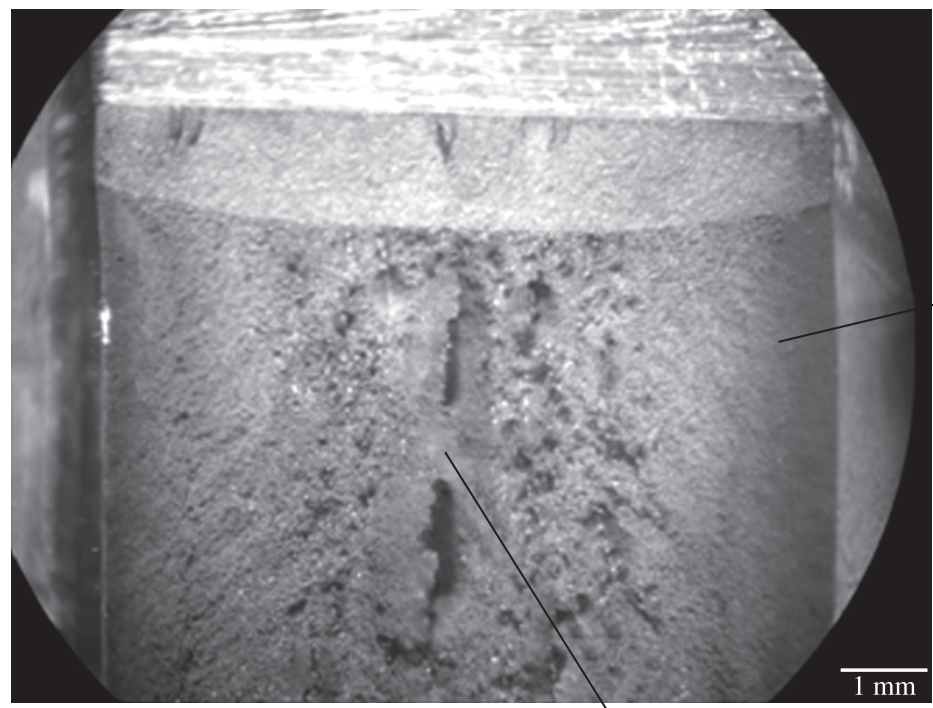

(a)

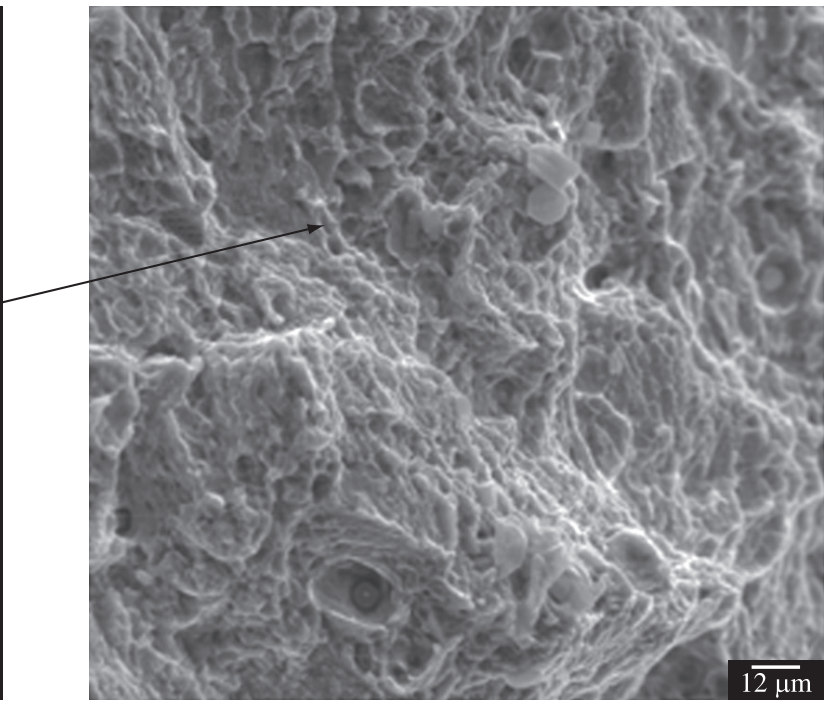

(b)

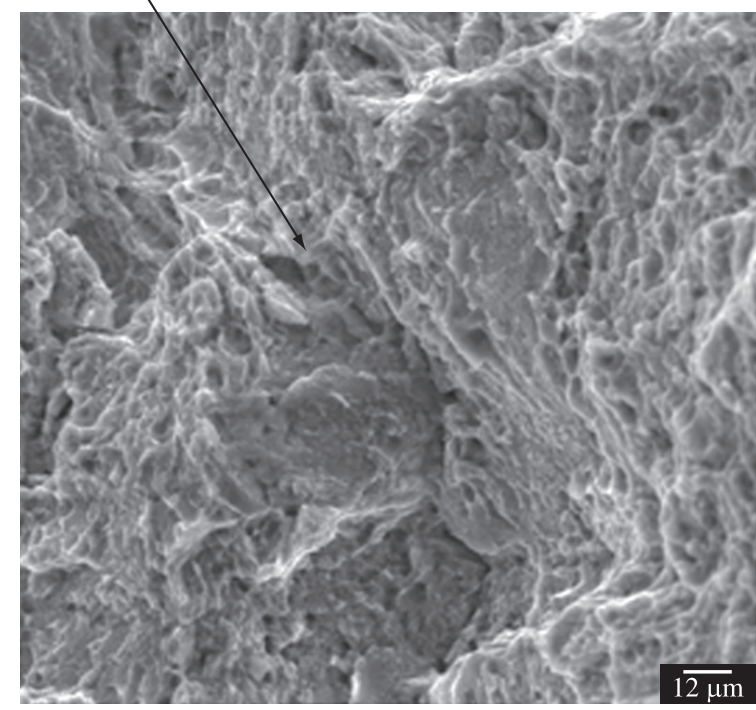

(c)

Figure 14. Fracture surface from steel $\mathrm{B}(0.017 \%$ of $\mathrm{P})$ austenitized at $850{ }^{\circ} \mathrm{C}$ and tempered at $530{ }^{\circ} \mathrm{C}$. a) General view of the fracture surface; b) detail from the instable crack growth; and c) detail from the fracture mode from the delamination. 
Table 3. Mechanical properties from tensile test, austenitizing and tempering temperatures and values of load $\left(\mathrm{P}_{\mathrm{Q}}\right)$ and toughness $\left(\mathrm{K}_{\mathrm{Q}}\right)$ for steels $\mathrm{B}$ and $\mathrm{D}$.

\begin{tabular}{lcc}
\hline \multicolumn{1}{c}{ Steels } & $\mathrm{B}$ & $\mathrm{D}$ \\
& $(0.017$ wt. $(\%) \mathrm{P})$ & $(0.031$ wt. $(\%) \mathrm{P})$ \\
\hline Quenching temperature $\left({ }^{\circ} \mathrm{C}\right)$ & 850 & 1000 \\
Tempering temperature $\left({ }^{\circ} \mathrm{C}\right)$ & 530 & 470 \\
Yield strength $(\mathrm{MPa})$ & $1262.3 \pm 8.5$ & $1430.3 \pm 9.2$ \\
Ultimate strength $(\mathrm{MPa})$ & $1327.3 \pm 15.9$ & $1547.0 \pm 6.2$ \\
$\mathrm{P}_{\mathrm{Q}}(\mathrm{kN})$ & $14.2 \pm 0.4$ & $10.3 \pm 0.3$ \\
$\mathrm{~K}_{\mathrm{Q}}[\mathrm{MPa} \sqrt{m}]$ & 98.8 & 71.7 \\
$(\mathrm{~W}-\mathrm{a}), \mathrm{B}, \mathrm{a}(\mathrm{mm})$ & 15.3 & 6.3 \\
\hline
\end{tabular}

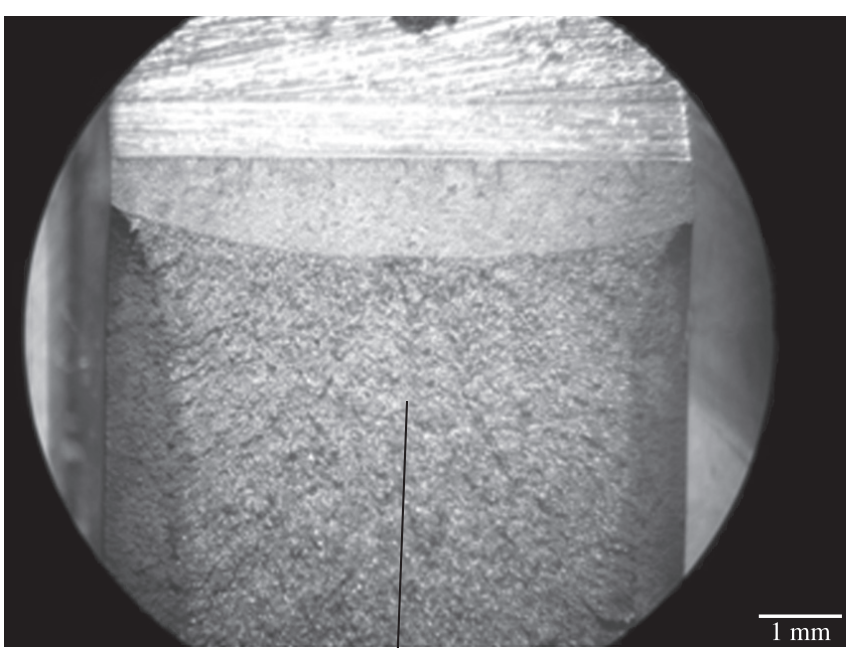

(a)

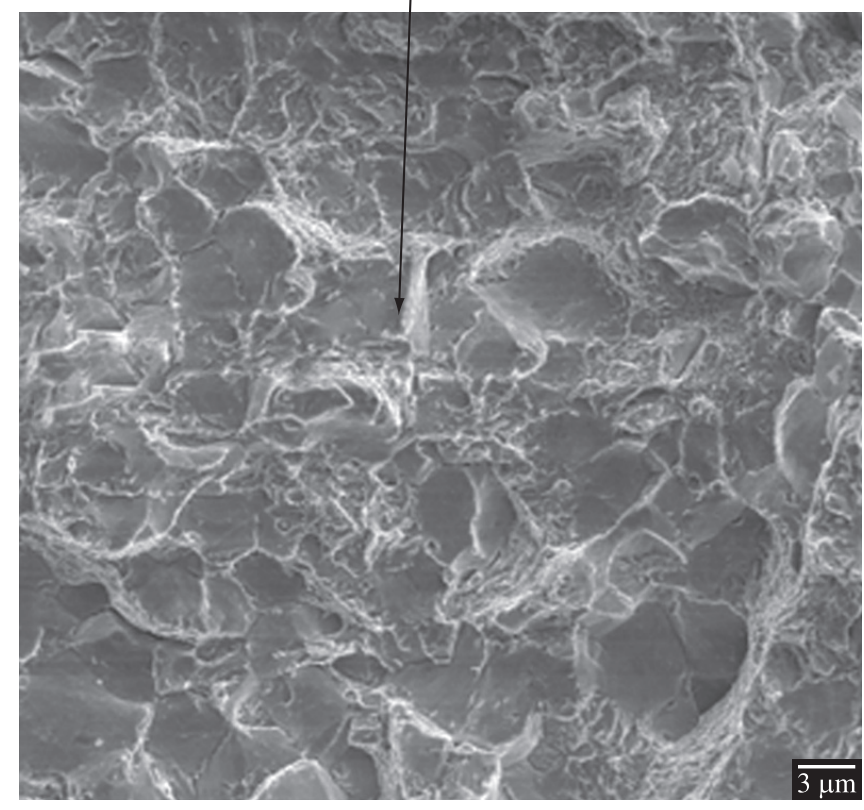

(b)

Figure 15. Fracture surface from steel D $(0.031 \%$ of $\mathrm{P})$ austenitized at $1000{ }^{\circ} \mathrm{C}$ and tempered at $470{ }^{\circ} \mathrm{C}$ : a) General view showing the notch, fatigue pre-crack and instable crack growth and b) Detail from the instable crack growth showing a brittle fracture mode.

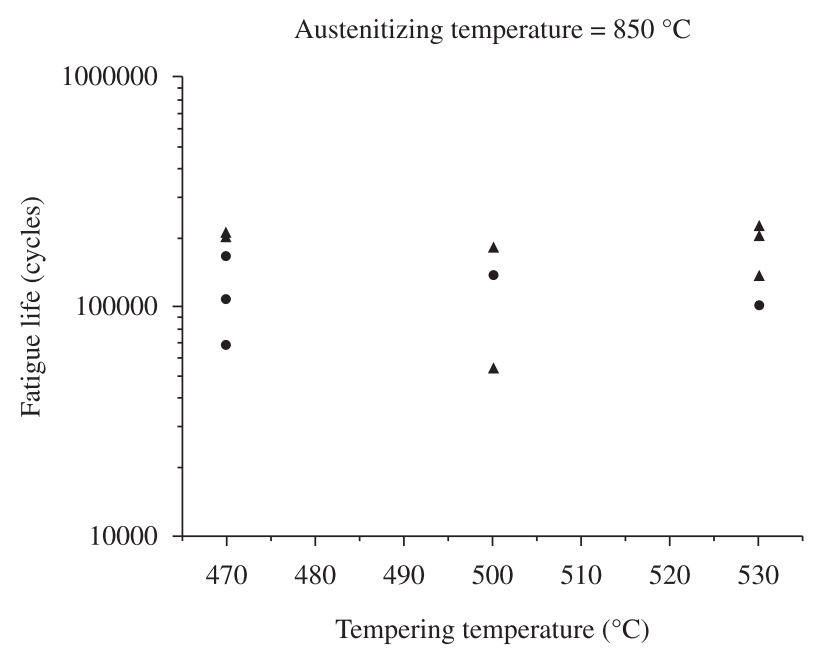

(a)

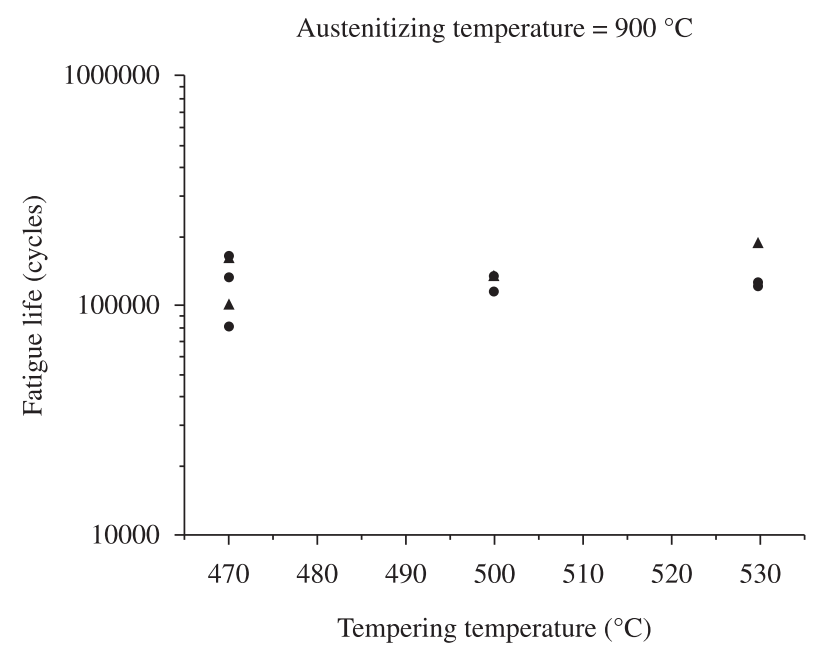

(b)

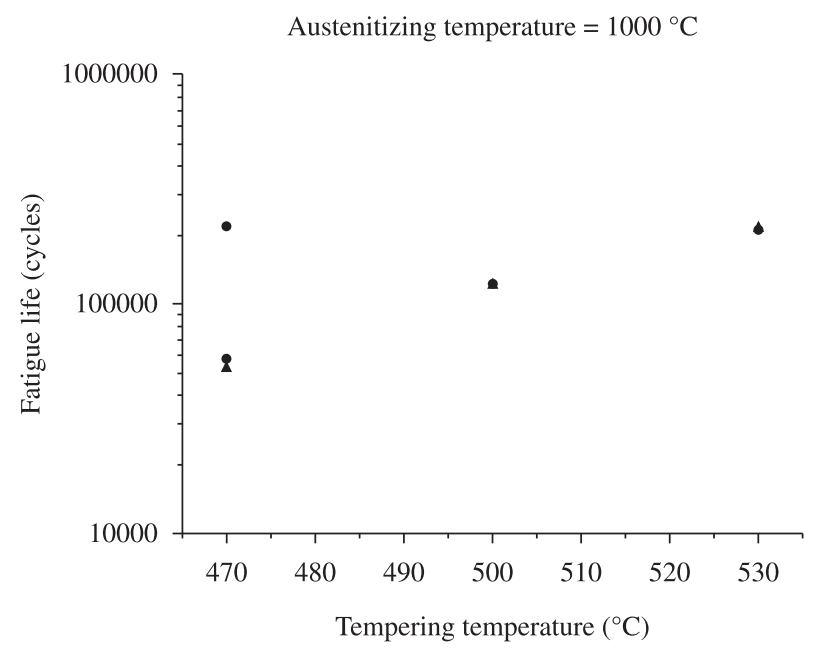

(c)

$\Delta 0.017 \% \mathrm{P} \bullet 0.031 \% \mathrm{P}$

Figure 16. Fatigue test results (S-N) performed in the heat-treated samples for austenitizing temperatures of a) $850{ }^{\circ} \mathrm{C}$; b) $900{ }^{\circ} \mathrm{C}$; and c) $1000{ }^{\circ} \mathrm{C}$ and a $\sigma$ máx $=130 \mathrm{MPa}$ applied in the center of the sheet and $\mathrm{R}=0.1$. 


\section{Conclusions}

From the results it is possible to conclude that the $\mathrm{P}$ content has a strong influence on the impact properties of the SAE 5160 steel, even if considered $\mathrm{P}$ content below the maximum allowable value $(0.03 \mathrm{wt}$. (\%)). The effect is more pronounced at lower quenching temperature $\left(850^{\circ} \mathrm{C}\right)$. For higher quenching temperatures (900 and $1000{ }^{\circ} \mathrm{C}$ ), the drop in the impact toughness is smaller.

Although, it was not possible to validate the fracture toughness results for steel B (quenched from $850{ }^{\circ} \mathrm{C}$ and tempered at $530{ }^{\circ} \mathrm{C}$ ) following the ASTM E1820, the $\mathrm{K}_{\mathrm{Q}}$ values were able to show a $30 \%$ drop in the stress intensity factor value when compared with the brittle steel (steel D quenched from $1000{ }^{\circ} \mathrm{C}$ and tempered at $470{ }^{\circ} \mathrm{C}$ ).

The fractographic analysis relates quite well with the absorbed energy and stress intensity factor values obtained for the steels analyzed, i.e., higher P content was related to larger percentile of intergranular fracture, as well as with increasing temperature for quenching.

Independently of the austenitizing and tempering temperatures, the values of high cycle fatigue life were not significantly affected by the embrittlement caused by higher levels of $\mathrm{P}$.

As a final conclusion, it was noticed that the $\mathrm{P}$ content has a very deleterious effect on the SAE 5160 steel and it is strongly recommended that spring steels must have $\mathrm{P}$ content as low as 0.01 wt. $(\%)$.

\section{Acknowledgements}

The authors would like to acknowledge Rassini-NHK Automotive for the support and the Materials, Aeronautics and Automotive Engineering Department at the Engineering School of São Carlos USP, for granting the use of its facilities.

\section{References}

1. Fuentes JJ, Aguilar HJ, Rodríguez JA and Herrera EJ. Premature fracture in automobile leaf springs. Engineering Failure Analysis, 2009; 16:648-655.

2. Krauss G. Steels: heat treatment and processing principles. Ohio: Materials Park ASM; 1995.
3. Hyde RS, Krauss G and Matlock DK. Quench embrittlement: intergranular fracture due to cementite and phosphorus in quenched carbon and steel steels. In: Proceedings of the $40^{\text {th }}$ Mechanical Working and Steel Processing Conference. 1998; Warrendale, PA. ISS. p. 921-928.

4. Reguly A, Strohaecker TR, Krauss G and Matlock DK. Quench embrittlement of hardened 5160 steel as a function of austenitizing temperature. Metallurgical and Materials Transactions A. 2004; 35A:153-162.

5. Pietikäinen J. Considerations about tempered martensite embrittlement. Materials Science and Engineering A. 1999; A273-275:466-470.

6. Zia-Ebrahimi F and Krauss G. Mechanisms of tempered martensite embrittlement in medium-carbon steels. Acta Metallurgical. 1984; 32:1767-1777.

7. Qing-fen L, Li L, Er-bao L, Dong L and Xiu-fang C. Temper embrittlement dynamics induced by non-equilibrium segregation of phosphorus in steel 12Cr1MoV. Scripta Materialia. 2005; 53:309-313.

8. ASM International Handbook Committee. Failure analysis and prevention. ASM Handbook. EUA; 2002; p. 691-692.

9. Krauss G. Deformation and fracture in martensitic carbon steels tempered at low temperatures. Metallurgical and Materials Transactions B. 2001; 32B:206.

10. Darwish FA, Pereira LC, Gatts C and Graça ML. On the tempered martensite embrittlement in AISI 4140 low alloy steel. Materials Science and Engineering A. 1991; A132: L5-L9.

11. Hyde RS, Krauss G and Matlock DK. Phosphorus and carbon segregation: effects on fatigue and fracture of gas-carburized modified 4320 steel. Metallurgical Materials Transactions A. 1994; 25A:1229-1240.

12. Apple CA and Krauss G. Microcracking and Fatigue in a Carburized Steel. Metallurgical Transactions A. 1973; 4:1195-1200.

13. Wu R, Freeman AJ and Olson GB. On the Electronic Basis of the Phosphorus Intergranular Embrittlement of Iron. Journal of Materials Resistance. 1992; 7(9):2403-2411.

14. Kunio T, Shimizu M, Yamada K, Enomoto M and Kawada Y. The Role of Prior Austenite Grains in Fatigue Crack Initiation and Propagation in Low Carbon Martensite. Fatigue Engineering Materials Structural. 1979; 2:237-249. 